HENZ, G.P.; CARDOSO, F.B. Absorção de água e proliferação de fungos em madeira de Pinus usada como embalagem para hortaliças. Horticultura Brasileira, Brasília, v.23, n.1, p. 138-142, jan.-mar. 2005.

\title{
Absorção de água e proliferação de fungos em madeira de Pinus usada como embalagem para hortaliças
}

\author{
Gilmar P. Henz'; Flávio B. Cardoso \\ ${ }^{1}$ Embrapa Hortaliças, C. Postal 218, 70359-970 Brasília-DF; E-mail: gilmar@cnph.embrapa.br; ${ }^{2}$ Faculdade da Terra de Brasília, Brasília-DF
}

\section{RESUMO}

A madeira é o material mais utilizado para embalagens de hortaliças no Brasil, principalmente por conta de seu baixo custo e alta resistência mecânica. Neste trabalho estimou-se a absorção e a perda progressiva de água de ripas de madeira de Pinus utilizadas na montagem de caixas do tipo " $\mathrm{K}$ " em três condições de umidade relativa e o crescimento de fungos em sua superfície. Trinta ripas novas de madeira de Pinus $(52 \times 6 \times 0,6 \mathrm{~cm})$ foram pesadas individualmente, imersas em água durante $1 \mathrm{~h}$ e pesadas novamente para avaliar a absorção de água. Em outro experimento, dez ripas foram incubadas ao acaso em cada uma das três câmaras úmidas $(61 \%$, $86 \%$ e $94 \%$ UR $)$ mantidas a $25^{\circ} \mathrm{C}\left( \pm 2^{\circ} \mathrm{C}\right)$. A perda progressiva de água foi avaliada por pesagens diárias das ripas individualmente e o desenvolvimento de fungos na madeira foi avaliado com uma escala de notas (0-3) durante oito dias. A madeira nova de Pinus pode absorver até $38 \%$ de seu peso em água, e permanecer úmida por vários dias de acordo com a condição de armazenamento. A umidade relativa do ambiente afetou a taxa de perda de água diária da madeira, sendo $4,7 \%, 2,5 \%$ e $1,0 \%$ respectivamente em $61 \%$ UR, $86 \%$ UR e 94\% UR, e ao final de oito dias alcançou 37,5\%, 19,9\% e 7,9\%, respectivamente. Os fungos predominantes foram Trichoderma harzianum e Rhizopus stolonifer, mas também observou-se crescimento de Aspergillus sp. e Penicillium sp. Para evitar a absorção de água pela madeira de Pinus e a proliferação de fungos em sua superfície, as hortaliças lavadas devem ser secadas ou submeter a madeira a um processo de impermeabilização.

Palavras-chave: caixa "K", transporte, pós-colheita.

\section{ABSTRACT}

Water absorption and fungi growth on pinewood used as crates for vegetable crops in Brazil

Pinewood is used for assembling the " $\mathrm{K}$ " box, a standard crate for packing, transporting and trading vegetables in Brazil. An estimate was made of water absorption and water loss by pinewood and the growth of fungi on its surface was determined under different $\mathrm{RH}$ conditions. Thirty pieces of pinewood $(52 \times 6 \times 0.6 \mathrm{~cm})$ were individually weighed, immersed in tap water during 1 hour and then weighed again to measure the water absorption. Ten pieces of pinewood of those previously immersed in water were kept at random in humid chambers $(61 \%, 86 \%$ and $94 \% \mathrm{RH})$ maintained at $25^{\circ} \mathrm{C}\left( \pm 2^{\circ} \mathrm{C}\right)$. Water loss was estimated daily by weighing individually each wood piece and fungi development was recorded by a fungi growth scale $(0=$ no growth; $3=>$ growth in $51 \%$ of the wood area), respectively. The pinewood can take up to $38 \%$ of its weight of water, and remain humid for a period of time enough to proliferate fungi in this surface. As expected, the relative humidity affected the daily rate of water loss, reaching $4.7 \%$ /day, $2.5 \%$ /day and $1.0 \%$ /day respectively at $61 \% \mathrm{RH}$, $86 \% \mathrm{RH}$ and $94 \% \mathrm{RH}$. After eight days, the pinewood water loss reached $37.5 \%$ at $61 \% \mathrm{RH}, 19.9 \%$ at $86 \% \mathrm{RH}$ and $7.9 \%$ at $94 \% \mathrm{RH}$. The predominant fungi growing on the wood surface were Trichoderma harzianum and Rhizopus stolonifer, but small colonies of Aspergillus sp. and Penicillium sp. were also identified. To avoid the water absorption by the pinewood, washed vegetables should be properly dried before packing or to waterproof the wood.

Keywords: packing, wooden crates, postharvest.

\section{(Recebido para publicação em 26 de abril de 2004 e aceito em 29 de outubro de 2004)}

$\mathrm{O}$ uso de embalagens para frutas e hortaliças tem sido intensamente discutido no Brasil nos últimos anos pelos distintos elos da cadeia de póscolheita, como produtores, CEASAs, atacadistas, varejistas, consumidores e técnicos de órgãos oficiais. Como resposta a esta demanda do setor hortícola, uma nova regulamentação do uso de embalagens para produtos hortícolas foi publicada no Diário Oficial em 12/11/ 2002 (MAPA, 2002). A Instrução Normativa $n^{\circ} 9$ do Ministério da Agricultura, Pecuária e Abastecimento (MAPA) foi o resultado de um trabalho conjunto da Secretaria de Apoio Rural e Cooperativismo (SARC), Agência Nacional de Vigilância Sanitária (ANVISA) e o Instituto Nacional de
Metrologia, Normalização e Qualidade Industrial (INMETRO). Esta instrução normativa está em vigor desde junho/ 2003 e alterou as portarias anteriores, regulamentando as embalagens para o acondicionamento, manuseio e comercialização dos produtos hortícolas in natura, ampliando as possibilidades do uso de diferentes tipos de embalagens em termos de materiais, como madeira, papelão e plástico, em tamanhos e formatos diversos, de acordo com cada produto (Ceagesp, 2002). A portaria anterior ( $\left.\mathrm{n}^{\circ} 127 / 91\right)$ recomendava o uso da caixa de madeira do tipo " $\mathrm{K}$ " para a maior parte das hortaliças, como tomate, pimentão, berinjela, jiló, maxixe, chuchu, abobrinha, mandioquinha-salsa e outras mais (MARA, 1991). A Ins- trução Normativa $n^{\circ} 9$ prevê o uso de embalagens com medidas externas paletizáveis em 1,0 x 1,2 m (medidas do palete padrão), de qualquer material, tanto descartável como retornável, contendo todas as informações obrigatórias sobre o produto em um rótulo (Ceagesp, 2004).

A madeira ainda é o material mais utilizado para embalagens de hortaliças no Brasil, sendo a maior parte proveniente de áreas de reflorestamento com espécies de Pinus e, em menor escala, com Eucalyptus. As principais vantagens da madeira são seu custo unitário mais baixo quando comparada com plástico e papelão ondulado, sua alta resistência mecânica e a possibilidade de reutilização, sendo um material 
reciclável (Topel, 1981; Bordin, 1999; Accarini et al., 2000; Luengo e Calbo, 2001). Outras vantagens da madeira como material de embalagens para produtos hortícolas é a sua versatilidade, sendo possível construir caixas com diferentes formatos com pouca tecnologia (Luengo e Calbo, 2001).

A madeira recém cortada pode apresentar teor de umidade variável, dependendo da espécie de árvore, período de cura ou secagem, condição e período de armazenamento. Considera-se como "seca" a madeira que possui cerca de $40 \%$ de umidade ou menos. Em condição ambiental com 60-70\% UR, a madeira conserva em torno de $12 \%$ de umidade. À medida que a umidade relativa do ambiente aumenta, a madeira também tende a absorver mais umidade, podendo alcançar de 25 a 30\% em um ambiente com 95\% UR.

A madeira de Pinus usada na confecção de caixas do tipo "K" apresenta algumas desvantagens em relação a outros tipos de materiais, como papelão ondulado e plástico. Os principais problemas da caixa "K" são seu formato e dimensões inadequadas, a superfície da madeira excessivamente áspera e a dificuldade de limpeza e higienização das embalagens. Como conseqüências danosas do uso de caixas de madeira do tipo "K" para produtos hortícolas, podem ocorrer diferentes tipos de danos mecânicos, como compressão, abrasão e cortes, e sua reutilização indiscriminada pode resultar na transmissão de doenças (Topel, 1981; Pichler, 1985; Bordin, 1999; Accarini et al., 2000; Cortez et al., 2000; Pereira e Calbo, 2000, Luengo e Calbo, 2001). Este tipo de caixa também pode absorver água e manter a umidade da madeira, o que aumenta o peso da embalagem e favorece o crescimento de fungos.

No Brasil, a CEAGESP em São Paulo foi pioneira na regulamentação do uso de caixas " $\mathrm{K}$ " novas e fechadas, com fiscalizações periódicas dos caminhões na entrada do mercado para verificação de suas dimensões e cumprimento das normas. Na maior parte dos estados brasileiros, as caixas " $\mathrm{K}$ ” são usadas sucessivamente para produtos de menor valor até serem definitivamente descartadas, o que pode ocorrer depois de dez vezes. Este uso contínuo pode incrementar o desenvolvimento e a transmissão de fungos causadores de doenças de pós-colheita em hortaliças, como Geotrichum, Alternaria, Rhizopus e Fusarium (Henz et al., 1993). A aspereza da madeira dificulta a limpeza e a sanitização das embalagens após cada uso, o que não ocorre com embalagens que apresentam superfícies mais lisas, como o plástico.

O uso da madeira de Pinus na confecção de embalagens para hortaliças no Brasil pode ser ampliado se forem avaliadas e adotadas medidas que minimizem suas limitações e desvantagens em relação aos outros materiais. Em outros países, como Chile e Espanha, as embalagens de madeira são muito importantes para produtos hortícolas porque além de utilizarem madeira de reflorestamento ainda aproveitam as partes menos nobres, não usadas na indústria moveleira (CEAGESP, 2003). No Brasil, os estudos realizados até agora com embalagens de madeira concentraram-se basicamente na incidência de danos mecânicos causados pela caixa " $K$ " em vários tipos de hortaliças em comparação com outros tipos de embalagens (Topel, 1981; Pichler, 1985; Pereira e Calbo, 2000; Luengo e Calbo, 2001).

Em diferentes mercados atacadistas brasileiros observa-se que caixas " $\mathrm{K}$ " feitas de madeira de Pinus novas usadas para hortaliças chegam ao mercado excessivamente úmidas e pesadas, principalmente em hortaliças lavadas. Em algumas destas caixas, é possível observar-se um crescimento inicial de fungos em sua superfície, que afeta sua aparência. $\mathrm{O}$ objetivo deste trabalho foi estimar a absorção e a perda progressiva de água e o desenvolvimento de fungos em ripas de madeira de Pinus novas utilizadas na montagem de caixas do tipo " $\mathrm{K}$ " em três condições de umidade relativa.

\section{MATERIAL E MÉTODOS}

\section{Absorção de água pela madeira}

A madeira de Pinus nova foi adquirida na CEASA de Anápolis-GO, no formato das ripas usadas para a montagem de caixas do tipo " $K$ ", de acordo com as dimensões da Portaria $n^{\circ} 127 /$
91 (Ministério da Agricultura, 1991). Foram selecionadas ripas de tamanho $(52 \times 6 \times 0,6 \mathrm{~cm})$ e aparência semelhante, coloração uniforme, sem nódoas de crescimento e sem nenhum tipo de sujeira na superfície. Para se obter diferentes condições de umidade relativa, foram construídas câmaras úmidas com um contentor plástico com capacidade para $32 \mathrm{~kg}$ (55 $\mathrm{cm}$ de comprimento, 35 $\mathrm{cm}$ de largura, $30 \mathrm{~cm}$ de altura). No fundo de cada caixa foram colocados papel toalha ou folhas de jornal umedecidas e as caixas foram envolvidas com sacos plásticos perfurados, variando-se o número e tamanho de furos para se obter diferentes condições de umidade relativa em seu interior. A temperatura e a umidade relativa no interior das câmaras úmidas foram monitoradas diariamente com um termohigrômetro. Em cada uma das três condições ambientais avaliadas (tratamento) foram acondicionadas ao acaso dez ripas de madeira de Pinus eqüidistantes $2 \mathrm{~cm}$ entre si, presas no interior das caixas somente pelas extremidades. As câmaras úmidas foram mantidas em um ambiente com temperatura média de $25^{\circ} \mathrm{C}\left( \pm 2^{\circ} \mathrm{C}\right)$, e apresentaram umidade relativa média de $61 \%$, $86 \%$ e $94 \%$ UR.

Crescimento de fungos na superfície da madeira

Em outro experimento, ripas de madeira de Pinus novas usadas para a confecção de caixas " $K$ ” foram imersas em água e posteriormente incubadas nas mesmas condições de umidade relativa e temperatura descritas para o experimento anterior. A avaliação da colonização da superfície da madeira por fungos foi feita diariamente durante oito dias utilizando-se uma escala de notas, onde $0=$ sem crescimento; $1=$ crescimento em até $10 \%$ da superfície da madeira; $2=$ de 11 a $50 \%$ da superfície; $3=$ mais de $51 \%$ da superfície. Cada uma das dez ripas foi avaliada individualmente nas duas faces, atribuindo-se uma nota média. Os fungos foram isolados, cultivados em meio de cultura (WA e BDA), identificados e posteriormente reinoculados em madeiras novas de Pinus borrifadas com álcool $95 \mathrm{GL}$, umedecidas em água e mantidas nas mesmas condições de umidade relativa descritas anteriormente. 


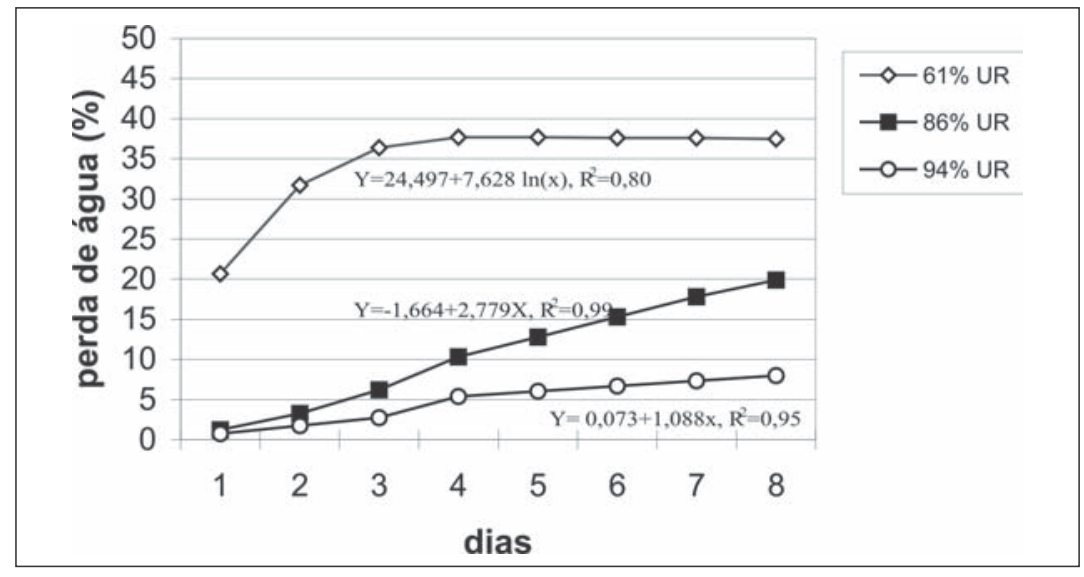

Figura 1. Perda progressiva de água de ripas novas de madeira de Pinus umedecidas em água durante $1 \mathrm{~h}$ e mantidas em três condições de umidade relativa $(61 \%, 86 \%$ e $94 \%)$ durante oito dias a $25^{\circ} \mathrm{C}$. Brasília, Embrapa Hortaliças, 2003.

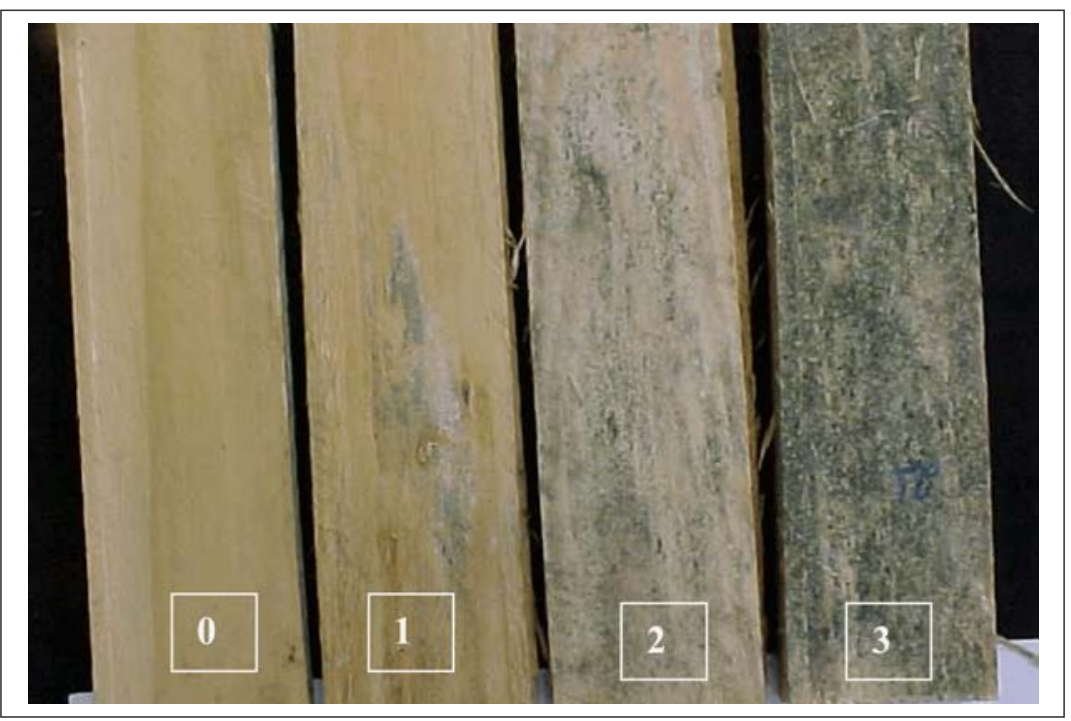

Figura 2. Escala de notas $(0=$ sem crescimento; $1=$ crescimento em até $10 \%$ da área da madeira; $2=11$ a $50 \%$ da área; $3=>51 \%$ da área) para avaliação da colonização de fungos na superfície da madeira de Pinus usada na confecção de embalagens para hortaliças. Brasília, Embrapa Hortaliças, 2003.

\section{RESULTADOS E DISCUSSÃO}

\section{Absorção e perda progressiva de água pela madeira de Pinus}

A madeira de Pinus utilizada na confecção de caixas do tipo "K" apresenta uma tendência de absorver água e de permanecer úmida dependendo da condição ambiental e do período de tempo. No presente trabalho, as ripas de Pinus chegaram a absorver até $38 \%$ de seu peso em água depois de permanecerem submersas durante $1 \mathrm{~h}$. Esta caracterís- tica da madeira de Pinus confirma observações empíricas de que caixas " $\mathrm{K}$ " novas absorvem facilmente água de hortaliças embaladas ainda úmidas, sem uma secagem adequada (Bordin, 1999; Accarini et al., 2000). De uma maneira geral, as variações no peso das hortaliciadas a outros fatores, como falta de padronização do tamanho da embalagem e tipo de produto. Aparentemente, o excesso de umidade de algumas hortaliças e a absorção de água pela madeira das caixas têm sido negligenciados pelos setores envolvidos no ças embaladas em caixas "K" são asso- beneficiamento e comercialização de hortaliças. $\mathrm{O}$ aumento no peso das caixas devido à absorção de água onera os custos de transporte e dificulta operações de carga e descarga das embalagens, principalmente para aquelas hortaliças com menor peso específico, como alface, pimentão, berinjela e jiló, por exemplo. Uma caixa " $\mathrm{K}$ " tem um peso líquido médio de $3 \mathrm{~kg}$, mas de acordo com os dados obtidos no presente estudo pode atingir $4,1 \mathrm{~kg}$ se for molhada e permanecer em um ambiente com alta umidade.

A umidade relativa do ambiente afetou a taxa de perda de água diária da madeira, sendo mais acentuada no ambiente mais seco e menor nos ambientes com maior umidade (Figura 1). Ao final de oito dias, a madeira de Pinus mantida no ambiente com $61 \%$ UR perdeu $37,5 \%$ de água, de forma muito rápida no primeiro dia $(20,6 \%)$ e no segundo dia $(31,7 \%)$ e estabilizando-se a partir do terceiro dia em diante, variando de $36,3 \%$ a $37,7 \%$ (Figura 1). A porcentagem de perda de água diária foi $4,7 \%$ e a curva de perda de água da madeira mantida a $61 \%$ UR ajustou-se a um modelo de regressão logarítmica $\left(\mathrm{Y}=24,497+7,628 \ln (\mathrm{x}), \mathrm{R}^{2}=0,80\right) . \mathrm{A}$ madeira de Pinus mantida a $86 \%$ UR perdeu $19,9 \%$ de seu peso após oito dias de forma constante em uma taxa diária de $2,5 \%$, ajustando-se a uma reta ( $\mathrm{Y}=$ $\left.1,664+2,779 x, R^{2}=0,99\right)$. Na condição de maior umidade (94\% UR), a madeira perdeu apenas $7,9 \%$ de seu peso ao final de oito dias, em uma taxa diária de $1,0 \%$, também ajustando-se a uma reta obtida através de regressão simples ( $\mathrm{Y}=$ $0,073+1,088 x, R^{2}=0,95$ ) (Figura 1).

Com base nestes resultados, podese explicar a grande variação de peso para algumas hortaliças embaladas em caixas "K" feitas com madeira de Pinus, principalmente para produtos lavados. $\mathrm{Na}$ CEASA-DF, o peso das caixas "K" para várias hortaliças nas cotações de preço é apresentado na forma de intervalo, com variações de 2 a $3 \mathrm{~kg} /$ caixa, como constatado para alface (caixa ' $\mathrm{K}$ ' de 4 a $6 \mathrm{~kg}$ ); beterraba (19 a $22 \mathrm{~kg}$ ); mandioquinha-salsa (20 a $22 \mathrm{~kg}$ ); cenoura e batata-doce (20 a $23 \mathrm{~kg}$ ) (CeasaDF, 2004). A absorção de água pela madeira também é preocupante porque mantem um microambiente úmido, fa- 
vorável ao desenvolvimento de fungos na superfície da madeira (Bordin, 1999; Accarini et al., 2000). Para evitar a absorção de água pela madeira de Pinus utilizada na montagem de caixas "K", as hortaliças lavadas devem ser submetidas à secagem. Outras opções são o tratamento da madeira com impermeabilizantes ou a submeter a madeira a um corte no beneficiamento que desfavoreça a absorção de água (Bordin, 1999; Accarini et al., 2000).

Crescimento de fungos na superfície da madeira

A escala com quatro notas (Figura 2) proposta para avaliar o crescimento dos fungos na superfície da madeira de Pinus mostrou-se de fácil uso e proporcionou leituras rápidas e eficientes. Os dois fungos predominantes na madeira foram identificados como Trichoderma harzianum, que apresentou colônias esverdeadas a amareladas, e Rhizopus stolonifer com micélio aéreo abundante de cor esbranquiçada e esporos escuros típicos (Domsch et al., 1980). Os dois fungos podem ser facilmente identificados visualmente pelo seu aspecto de crescimento, marcadamente diferenciado. Também constatou-se o crescimento de pequenas colônias de Penicillium sp. e Aspergillus sp. Todos estes fungos foram cultivados em meio de cultura, e inoculados com um "plug" de micélio em madeira de Pinus nova mantida em câmara úmida e apresentaram crescimento além do ponto de inoculação.

Já a partir do segundo dia observouse crescimento de fungos na superfície da madeira nas umidades relativas mais elevadas (Figura 3). Na madeira mantida na umidade mais baixa $(61 \%)$ observou-se um pequeno crescimento de fungos ao final de um período de oito dias (Figura 3), com nota variando de 0,3 (Rhizopus) a 0,4 (Trichoderma); nesta condição também desenvolveram-se outros fungos, como Penicillium spp. e Aspergillus spp. Trichoderma spp. foi o fungo de crescimento e colonização mais rápidas nas umidades relativas mais elevadas, colonizando $100 \%$ da área da madeira mantida a 94\% UR em uma semana (Figura 3). O fungo Rhizopus desenvolveu-se menos na madeira onde

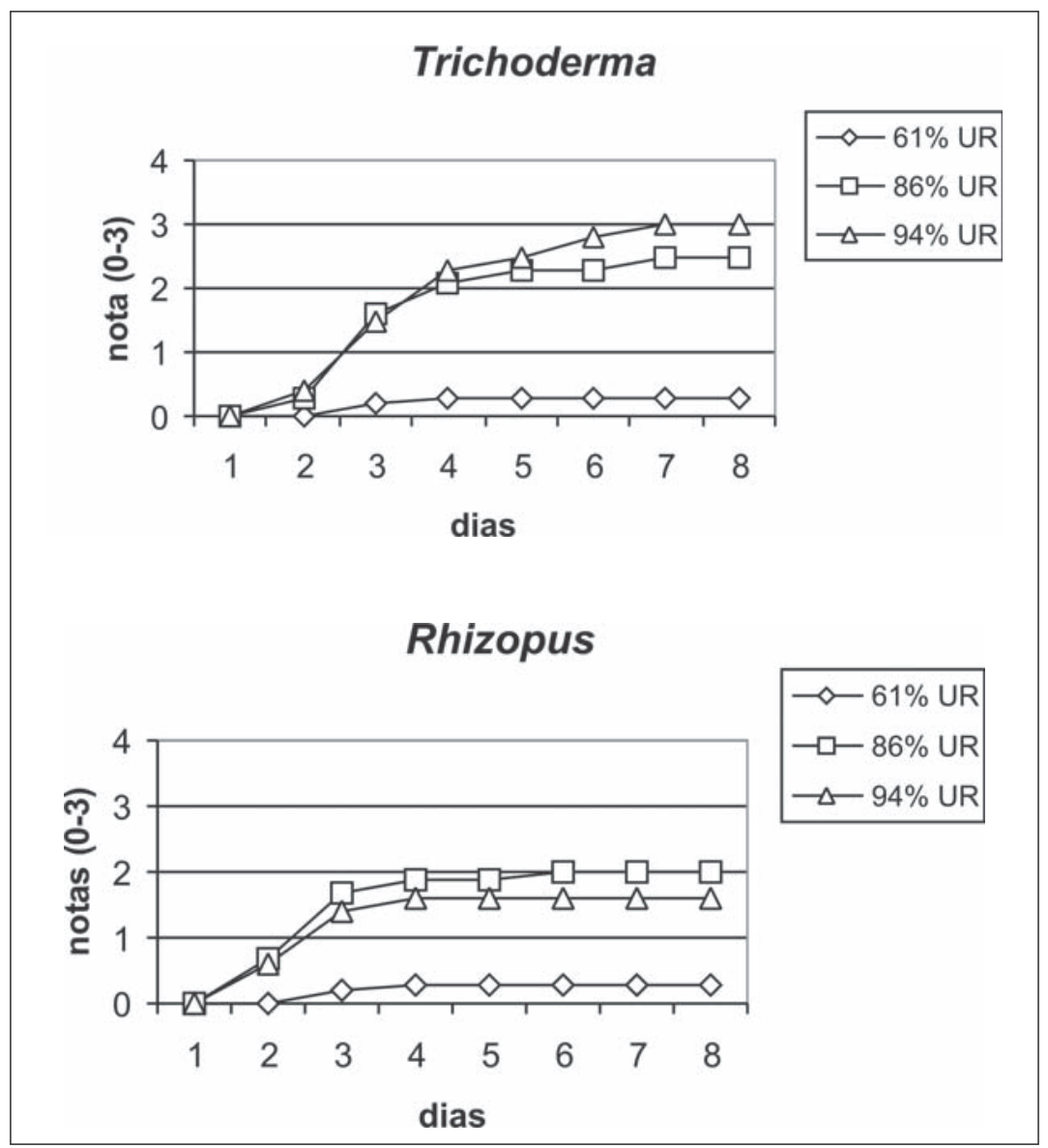

Figura 3. Crescimento de Trichoderma harzianum e Rhizopus stolonifer uma escala de notas $(0=$ sem crescimento; $3=$ crescimento $>50 \%$ área $)$ em madeira de Pinus mantidas em três condições de umidade relativa $(61 \%, 86 \%$ e $94 \%)$ durante oito dias a $25^{\circ} \mathrm{C}$. Brasília, Embrapa Hortaliças, 2003.

Trichoderma predominou, como constatado na condição de $94 \%$ UR.

Os dois fungos predominantes na superfície da madeira de Pinus não apresentam uma grande ameaça do ponto de vista fitopatológico, e causam mais danos à aparência das caixas propriamente dita. Trichoderma harzianum somente é capaz de causar doença em plântulas de milho e está associado ao apodrecimento de raízes de mandioca (Domsch et al., 1980) e Rhizopus stolonifer depende de ferimentos para causar doenças em hortaliças (Agrios, 1997). Trichoderma harzianum produz enzimas capazes de degradar celulose, um dos principais componentes da madeira e assim afetar negativamente sua qualidade e a possibilidade de reutilização. Este fungo também tem propriedades antagonistas contra vários outros fungos, como Aspergillus,
Pythium, Rhizoctonia e Candida, e por esta razão é utilizado para controle biológico. Os dois fungos podem ser considerados como ótimos colonizadores de vários tipos de substratos devido principalmente a algumas características competitivas. Tanto Trichoderma como Rhizopus são facilmente disseminados por esporos aéreos, rápido crescimento e abundante produção de inóculo, além de serem adaptados a vários tipos de ambiente.

Com base nestes resultados, podese inferir que a madeira de Pinus nova utilizada na confecção de caixas " $\mathrm{K}$ " absorve muita água e pode manter-se úmida por períodos de tempo relativamente longos, de acordo com a temperatura e umidade relativa do ambiente. Esta condição é muito favorável para o desenvolvimento de fungos na superfície da madeira, o que pode afetar sua 
aparência e reduzir sua reutilização ou eventualmente causar doenças pós-colheita, quando houver incidência de ferimentos nas hortaliças durante o transporte ou o armazenamento. Como alternativas para a solução deste problema, a madeira de Pinus pode ser melhor beneficiada, com um corte que a deixe menos áspera e menos propensa a absorver água, ou avaliar uma maneira de impermeabilizar sua superfície.

\section{AGRADECIMENTOS}

Os autores agradecem a Prof ${ }^{a}$ Maria Menezes e a doutoranda Ilka Márcia R. de Souza Serra (Depto. Fitossanidade, UFRPE, Recife-PE) pela identificação dos isolados de Trichoderma.

\section{LITERATURA CITADA}

ACCARINI, J.H.; MAZOCATO, M.A.; COSTA, O.G.P.; LUENGO, R.F.A. Pontos de estrangulamento: os obstáculos internos e externos representam vicissitudes a serem vencidas pela olericultura brasileira. Agroanalysis, v.20, n.2, p.32-36, 2000.

AGRIOS, G.N. Plant Pathology. San Diego: Academic Press, 1997. 635 p.
ASGROW DO BRASIL SEMENTES. Embalagens para olerícolas: alternativas, funções e problemas na legislação. A Semente, Campinas, v.14, n.41, p.3, 1995.

BORDIN, M.R. Embalagem levada a sério: o CETEA projeta embalagens baseadas em resultados práticos, o que proporciona rapidez e baixo custo de desenvolvimento. Agroanalysis, v.19, n.6, p.46-48, 1999.

CEAGESP. Novidades do mercado: caixa de madeira. Disponível em <http:// www.ceagesp.com.br/nov.htm $>$ Consultado em: 12 set.2003. 18 p.

CEAGESP. Como atender às exigências de rotulagem. Disponível em <http:// www.ceagesp.com.br/nov.htm $>$ Consultado em: 09 jan. 2004. 18 p.

CEASA-DF. Mercado - cotações de preço no atacado. Disponível em <http://www.ceasa-df.org.br/ mercado. $h t m>$ Consultado em: 21 jan 2004. 4 p. CHITARRA, M.I.F. Embalagem e transporte de frutos. Informe Agropecuário, Belo Horizonte, v.17, n.179, p.19-26, 1994.

CORTEZ, L.A.B.; CASTRO, L.R.; ABRAHÃO, R.F. Subsídios técnicos para o projeto de embalagens para flores, frutas e hortaliças considerando os requerimentos de refrigeração. Revista Frutas e Legumes, São Paulo, v.2, n.7, p.16-21, 2000.

DOMSCH, K.H.; GAMS, W.; ANDERSON, T.H. Compendium of Soil Fungi. London: Academic Press, 1980. 859 p.

HENZ, G.P.; HORIUCHI, S.; LIMA, M.F. Ocorrência de doenças pós-colheita em tomate relacionadas à reutilização da caixa "K". Horticultura Brasileira, Brasília, v.11, n.1, p.75, 1993. Resumo.
LUENGO, R.F.A.; CALBO, A.G. Armazenamento de hortaliças. Brasília: Embrapa Hortaliças, 2001. 242 p. LUENGO, R.F.A.; FURUYA, T.; SILVA, J.O.L. Embalagem ideal para o transporte do tomate 'Santa Clara'. Pesquisa Agropecuária Brasileira, Brasília, v.32, n.5, p.517-520, 1997.

MARA. MINISTÉRIO DA AGRICULTURA E DA REFORMA AGRÁRIA. Portaria n ${ }^{\circ} 127$. Diário Oficial, de 04/10/91.

MAPA. MINISTÉRIO DA AGRICULTURA PECUÁRIA E DO ABASTECIMENTO. Instrução Normativa Conjunta SARC/ANVISA/ INMETRO No 9. Diário Oficial, de 12/11/2002.

MOURAD, A.L. Embalagem para hortícolas. In: ENCONTRO DE APLICAÇÃO DE PLÁSTICO NA AGRICULTURA, 1., 1996, Campinas, SP. Resumo... Campinas: UNICAMP, 1996. p.10-15. PEREIRA, A.V.; CALBO, A.G. Elastic stresses and plastic deformations in 'Santa Clara' tomato fruits caused by package dependent compression. Pesquisa Agropecuária Brasileira, Brasília, v.35, n.12, p.2429-2436, 2000.

PICHLER, E.F. Comparação de desempenho de caixas de papelão e de madeira para tomate. São Paulo: IPT, 1985. 18 p. (Relatório de Pesquisa, 21889).

TOPEL, R.M.M. Estudos de embalagens para produtos hortícolas: o caso da caixa K. São Paulo, 1981. 30 p (Relatório de Pesquisa, 17/81). 